\title{
Eurolntervention
}

\section{Between-centre reproducibility of volumetric intravascular ultrasound radiofrequency-based analyses in mild-to- moderate coronary atherosclerosis: an international multicentre study}

Jennifer Huisman ${ }^{1}$, MD, MSc; Rasmus Egede², MD; Adam Rdzanek ${ }^{3}$ MD; Dirk Böse ${ }^{4}$, MD; Raimund Erbel ${ }^{4}, \mathrm{MD}$; Janusz Kochman³, MD, PhD; Lisette Okkels Jensen², MD, PhD; Job van de Palen ${ }^{5,6}$, MSc, PhD; Marc Hartmann1, MD, PhD; Gary S. Mintz ${ }^{7}$, MD; Clemens von Birgelen ${ }^{1,8 *}, \mathrm{MD}, \mathrm{PhD}$

1. Department of Cardiology, Thoraxcentrum Twente, Medisch Spectrum Twente, Enschede, The Netherlands; 2. Department of Cardiology, Odense University Hospital, Odense, Denmark; 3. Department of Cardiology, Central University Hospital, Warsaw, Poland; 4. Department of Cardiology, Westdeutsches Herzzentrum Essen, Universitätsklinikum Essen-Duisburg, Germany; 5. Department of Epidemiology, Medisch Spectrum Twente, Enschede, The Netherlands; 6. Department of Research Methodology, Measurement and Data Analysis, University of Twente, Enschede, The Netherlands; 7. Cardiovascular Research Foundation, New York, USA; 8. MIRA - Institute for Biomedical Technology and Technical Medicine, University of Twente, Enschede, The Netherlands

The authors have no conflict of interest to declare.

\section{KEYWORDS \\ Coronary disease, \\ intravascular \\ ultrasound, \\ ultrasonics, \\ radiofrequency, \\ virtual histology, \\ measurement \\ reproducibility}

\begin{abstract}
Aims: To assess for the first time in a multicentre design the between-centre reproducibility of volumetric virtual histology intravascular ultrasound (VH-IVUS) measurements with a semi-automated, computerassisted contour detection system in mild-to-moderately diseased coronary segments.

Methods and results: Analysts of four European IVUS centres performed independent IVUS analyses (in total 7,188 cross-sectional analyses) and obtained volumetric data to evaluate the reproducibility of volumetric VH-IVUS measurements in 36 coronary segments (length $20.0 \pm 0.4 \mathrm{~mm}$ ) from patients with stable angina. Geometric and compositional VH-IVUS measurements were highly correlated for the different comparisons. Overall intraclass correlation for vessel, lumen, plaque volume and plaque burden were $0.98,0.92$ 0.95, and 0.86, respectively; for fibrous, fibro-lipidic, necrotic core and calcified volumes overall intraclass correlations were $0.95,0.93,0.99$, and 1.00 , respectively. There were significant but small differences for vessel, lumen, fibrous and calcified volumes, and there was no significant difference for plaque volume. Of the plaque components necrotic core and calcified volume showed on average the highest reproducibility.

Conclusions: These findings underline the necessity to centrally analyse IVUS data obtained in multicentre studies addressing mild-to-moderately diseased coronary arteries. In addition, pooling VH-IVUS data from different studies, analysed at different centres, may be problematical.
\end{abstract}

\footnotetext{
* Corresponding author: Department of Cardiology, Thoraxcentrum Twente, Haaksbergerstraat 55, 7513ER Enschede, The Netherlands E-mail: c.vonbirgelen@mst.nl
} 


\section{Abbreviations \\ IVUS intravascular ultrasound \\ $\mathrm{VH} \quad$ virtual histology}

\section{Introduction}

Greyscale intravascular ultrasound (IVUS) permits accurate quantification of vessel and plaque dimensions, but it has significant limitations in the assessment of plaque composition. ${ }^{1-4}$ Virtual Histology-IVUS (VH-IVUS) incorporates analysis of radiofrequency IVUS data to provide a better assessment of the coronary plaque components such as necrotic core and densely calcified area. ${ }^{5-14}$ Volumetric measurements are known to have a higher measurement reproducibility than cross-sectional area measurements which is likely the result of averaging differences between individual cross-sectional area measurements. ${ }^{15,16}$

VH-IVUS includes a semi-automated analyse function (i.e., computerassisted contour detection) to provide volumetric data that are increasingly used for the assessment of coronary atherosclerosis and as endpoints of pharmacological studies for the treatment of coronary atherosclerosis. ${ }^{1,17-21}$ However, because recent serial VH-IVUS studies such as the IBIS-2 trial revealed only small changes in plaque volume and composition ${ }^{20}$, the reproducibility of VH-IVUS becomes an important issue. ${ }^{1,14,22,23}$ In a previous study in mild-to-moderately diseased coronary segments, we have demonstrated that the interobserver variability of volumetric geometric and compositional $\mathrm{VH}$ IVUS measurements by two analysts from the "same" centre is very acceptable. ${ }^{22}$ But so far, the between-centre reproducibility of $\mathrm{VH}$ IVUS measurements has never been investigated.

Therefore, in the present study we assessed the "between-centre" reproducibility of volumetric VH-IVUS measurements in mild-tomoderately diseased coronary segments by comparing data from repeated analyses as performed by independent analysts at four different European IVUS-centres.

\section{Methods}

\section{Study population}

To assess the between-centre reproducibility of segmental volumetric VH-IVUS data analysis of mild-to-moderately diseased atherosclerotic human coronary arteries, we performed IVUS analyses in $20 \mathrm{~mm}$-long segments of non-target and non-treated coronary arteries in patients with stable angina pectoris. Segments had to meet the following inclusion criteria: absence of ambiguous or significant coronary lesions (i.e., mild-to-moderate atherosclerotic disease), severe plaque calcification, major vessel tortuosity, and/or major side-branches. In this multicentre study design, four experienced analysts independently performed VH-IVUS analyses of all segments included in the study. Each centre was invited to submit IVUS pullbacks of 10 coronary segments obtained from patients in sinus rhythm in whom a clinically driven cardiac catheterisation required IVUS assessment. Participating centres were Odense University Hospital, Odense, Denmark; Essen University Hospital, Essen, Germany; Central University Hospital, Warsaw, Poland; and Thoraxcentrum Twente, Enschede, The Netherlands.

\section{IVUS data acquisition}

IVUS data were acquired with ECG-gating and commercially available phased-array IVUS catheters (Eagle Eye ${ }^{\circledR}$ Gold 2.9 Fr $20 \mathrm{MHz}$; Volcano Corporation, Rancho Cordova, CA, USA) with a dedicated console.2,24 The IVUS transducer was advanced $\geq 10 \mathrm{~mm}$ distal to the most distal side-branch. Angiographic cine runs were performed to define the position of the IVUS transducer. After intracoronary injection of $200 \mu \mathrm{g}$ nitroglycerine, a continuous pullback of the IVUS catheter was performed using a motorised pullback device at $0.5 \mathrm{~mm} / \mathrm{s}$ (TrackBack-II; Volcano Corporation, Rancho Cordova, CA, USA). IVUS image data were stored on digital video disk (DVD) for offline analysis.

\section{VH-IVUS data analysis}

Technique and the validation of $\mathrm{VH}$-IVUS have previously been described.6,12 In brief, spectral IVUS radiofrequency data were reconstructed to generate tissue maps in order to classify the plaque in four major components: calcium; fibro-lipidic; fibrous; and necrotic core. Tissue components were displayed according to a colour code (white, light-green, green, and red, respectively).

VH-IVUS analysis of all cases was performed offline by one experienced IVUS analyst per centre (Figure 1). The IVUS

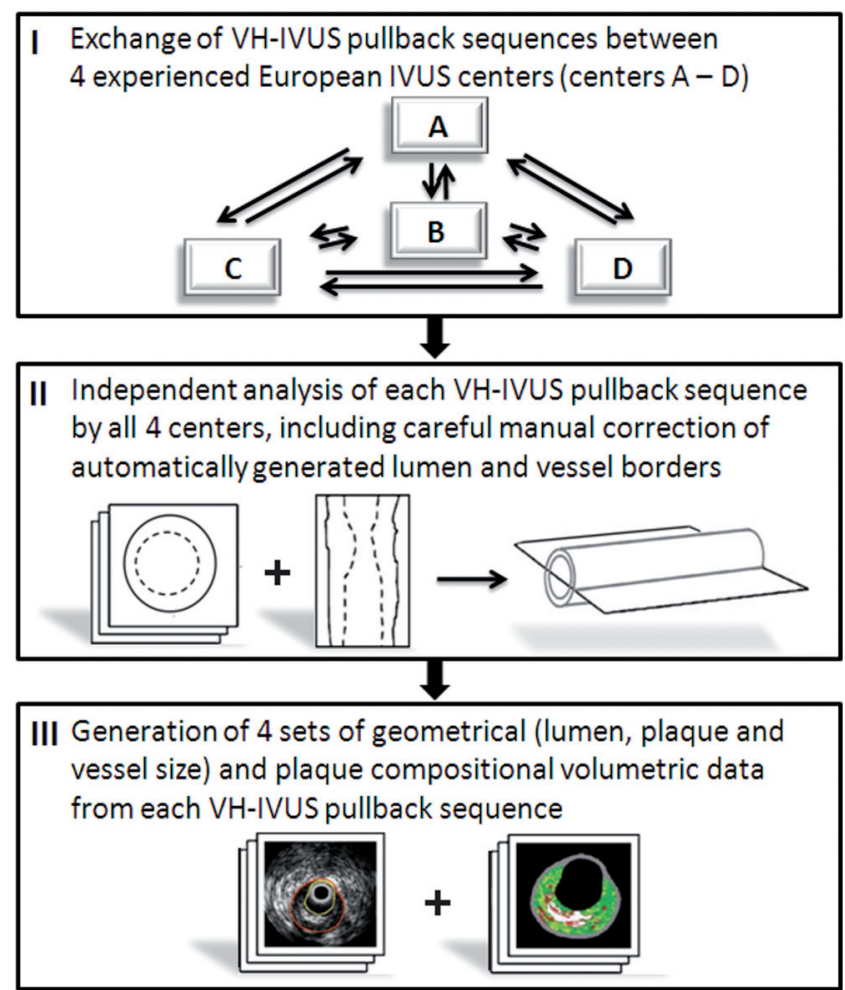

Figure 1. Image acquisition and analysis. Each centre (A-D) performed motorized pullbacks at $0.5 \mathrm{~mm} / \mathrm{s}$, image frames were acquired at the time of the R-wave peak. These pullback sequences (obtained from 10 patients with stable angina) were exchanged in order to obtain a "pullback pool" of 40 pullbacks which each analyst independently analyzed (I). Automated contour detection of the lumen and vessel border was performed on all frames using the $\mathrm{VH}$-images and software (II). Volumetric VH-IVUS data of the geometric and compositional data were automatically generated for the analyzed segment based on the application of the trapezium method to the cross-sectional area measurements (III). 
sequences were provided with a predefined region of interest that contained mild-to-moderate atherosclerotic disease (no target for percutaneous coronary interventions). Segments were located between two adjacent side-branches and contained no major calcification that could have limited reliable detection of the external vascular boundary.

IVUS measurements, both geometric and compositional measurements, were made using the $\mathrm{VH}$-images and software. The lumen and vessel borders were traced using a semi-automated computer-assisted contour detection program (Volcano pcVH software program version 2.2; Corporation, Rancho Cordova, CA, USA); to exclude potential between version differences of the analysis software, all four centres used the same (latest) version of the analysis software. The leading edge of the blood-intima acoustic interface and the leading edge of the media-adventitia interface were automatically detected to define the lumen and vessel borders, respectively, and manually corrected as required. Plaque and media was used as a measure of atherosclerotic plaque and was calculated as the difference between vessel and lumen cross-sectional area. For each coronary segment, volumetric data of the vessel, lumen, plaque and plaque burden, as well as fibrous, fibro-lipidic, necrotic core, and calcified tissue were obtained from the application of the trapezium method to the cross-sectional area measurements. The $\mathrm{pcVH}$ software program uses this method that considers the exact spacing between image frames to calculate volumes from the crosssectional area data in the most accurately way. In addition, the relative amount of the four plaque components was calculated.

In order to assess the between-centre reproducibility of volumetric VH-IVUS analyses, comparisons were performed on a 2-observer basis (i.e., centre $A$ versus $B, C$ and $D$ respectively; centre $B$ versus $C$ and $D$ respectively; and centre $C$ versus $D$ ).

\section{Statistical analysis}

Statistical analysis was performed with SPSS 15.0 (SPSS Inc., Chicago, IL, USA). Dichotomous variables are presented as frequencies, while quantitative data are presented as mean $\pm 1 S D$ (or \pm 1SEM). Quantitative data were compared by use of a paired ttest after normality of the data was confirmed. A two-sided $p$-value $<0.05$ was considered as significant. According to Bland and
Altman, the agreement between two measurements was assessed by determining the mean $\pm 2 S D$ of the between measurement differences. ${ }^{25}$ Intra-class correlations were calculated for comparisons at individual level. An intraclass correlation $>0.90$ was considered good.

\section{Results}

\section{Study population}

From the 40 segments (10 per centre) submitted for the purpose of this study, four segments did not meet the inclusion criteria (three major side branches and one patient with unstable angina) and were not included in the analysis. A total of 36 mild-to-moderately atherosclerotic coronary segments (10 right; 18 left anterior descending; and 8 left circumflex coronary arteries) from 36 patients with stable angina (27 males; $59 \pm 8$ years old) were studied. Seventy-eight percent of the patients were on statin therapy prior to the cardiac catheterisation, and $17 \%$ were diabetics. There was no complication related to IVUS imaging.

\section{VH-IVUS analysis and data}

Each of the four analysts performed an independent analysis of each of the 36 coronary segments and obtained volumetric data to evaluate the reproducibility of volumetric VH-IVUS measurements $(50 \pm 11$ frames/segment). This approach required the analysis of a total of 7,188 cross-sectional frames (1,797 frames per analyst). Manual correction of the automatic border detection was required in almost all frames for a total analysis time of $59 \pm 5 \mathrm{~min} /$ segment. The length of the analysed segments was 20.0 $\pm 0.4 \mathrm{~mm}$ (range: 19.2-20.7 mm). On average, the atherosclerotic segments contained predominantly fibrous (57.8\%), fibro-lipidic (17.9\%), and necrotic core (16.0\%) tissue. Geometric and compositional IVUS data obtained by the analysts of the four different centres (A-D) are presented in Table 1.

\section{Geometry}

Geometric measurements were highly correlated for the different comparisons. There were significant differences for vessel and lumen volumes; however, these differences were relatively small (Table 2). Plaque volume showed no significant between-centre

\section{Table 1. VH-IVUS data from four different centres (A-D).}

\begin{tabular}{|c|c|c|c|c|}
\hline & A & B & C & D \\
\hline \multicolumn{5}{|l|}{ Vessel geometry } \\
\hline Vessel volume $\left(\mathrm{mm}^{3}\right)$ & $187.3 \pm 40.7$ & $191.7 \pm 43.7$ & $192.0 \pm 42.4$ & $184.4 \pm 39.6$ \\
\hline Lumen volume $\left(\mathrm{mm}^{3}\right)$ & $95.4 \pm 24.6$ & $101.6 \pm 24.7$ & $99.7 \pm 24.2$ & $93.6 \pm 22.0$ \\
\hline Plaque volume $\left(\mathrm{mm}^{3}\right)$ & $91.9 \pm 27.3$ & $90.1 \pm 27.4$ & $92.3 \pm 27.8$ & $90.9 \pm 26.8$ \\
\hline Plaque burden (\%) & $48.8 \pm 8.2$ & $46.7 \pm 7.4$ & $47.8 \pm 7.9$ & $48.9 \pm 7.6$ \\
\hline \multicolumn{5}{|l|}{ Plaque composition } \\
\hline Fibrous volume $\left(\mathrm{mm}^{3}\right)$ & $31.6 \pm 13.7$ & $30.0 \pm 13.7$ & $30.9 \pm 14.4$ & $30.5 \pm 13.8$ \\
\hline Fibrous volume $(\%)$ & $58.3 \pm 7.9$ & $57.6 \pm 17.6$ & $57.8 \pm 8.1$ & $57.6 \pm 8.2$ \\
\hline Fibro-lipidic volume $\left(\mathrm{mm}^{3}\right)$ & $10.2 \pm 7.4$ & $9.6 \pm 8.1$ & $9.9 \pm 8.8$ & $9.6 \pm 7.2$ \\
\hline Fibro-lipidic volume (\%) & $18.4 \pm 9.9$ & $17.6 \pm 10.1$ & $17.5 \pm 9.9$ & $18.0 \pm 16.1$ \\
\hline Necrotic core volume $\left(\mathrm{mm}^{3}\right)$ & $9.2 \pm 8.8$ & $8.9 \pm 7.8$ & $9.1 \pm 7.9$ & $9.3 \pm 8.6$ \\
\hline Necrotic core volume (\%) & $15.6 \pm 8.6$ & $16.2 \pm 8.8$ & $16.3 \pm 8.9$ & $16.1 \pm 8.8$ \\
\hline Calcium volume $\left(\mathrm{mm}^{3}\right)$ & $4.4 \pm 4.2$ & $4.6 \pm 4.3$ & $4.6 \pm 4.3$ & $4.5 \pm 4.2$ \\
\hline Calcium volume (\%) & $7.8 \pm 6.6$ & $8.6 \pm 6.9$ & $8.4 \pm 6.7$ & $8.2 \pm 6.7$ \\
\hline
\end{tabular}

Values are mean \pm standard deviation. 
Table 2. Measurement differences of VH-IVUS data derived from four different centres (A-D).

\begin{tabular}{|c|c|c|c|c|c|c|}
\hline & \multicolumn{3}{|c|}{$\begin{array}{c}\text { A } \\
\text { Versus* }\end{array}$} & \multicolumn{2}{|c|}{$\begin{array}{c}\text { B } \\
\text { Versus* }\end{array}$} & \multirow{2}{*}{$\begin{array}{c}\text { C } \\
\text { Versus* } \\
\text { D }\end{array}$} \\
\hline & B & C & D & C & D & \\
\hline \multicolumn{7}{|l|}{ Vessel geometry } \\
\hline$\Delta$ Vessel volume $\left(\mathrm{mm}^{3}\right)$ & $\begin{array}{c}-4.3 \pm 0.9 \\
P<0.01\end{array}$ & $\begin{array}{c}-4.7 \pm 0.8 \\
P<0.01\end{array}$ & $\begin{array}{l}2.9 \pm 0.9 \\
P<0.01\end{array}$ & $\begin{array}{c}-0.3 \pm 0.9 \\
P=0.7\end{array}$ & $\begin{array}{l}7.2 \pm 1.1 \\
P<0.01\end{array}$ & $\begin{array}{l}7.6 \pm 0.9 \\
P<0.01\end{array}$ \\
\hline$\Delta$ Lumen volume $\left(\mathrm{mm}^{3}\right)$ & $\begin{array}{c}-6.1 \pm 1.6 \\
P<0.01\end{array}$ & $\begin{array}{c}-4.2 \pm 1.4 \\
P=0.05\end{array}$ & $\begin{array}{c}1.9 \pm 1.2 \\
P=0.1\end{array}$ & $\begin{array}{c}1.9 \pm 1.5 \\
P=0.2\end{array}$ & $\begin{array}{l}8.0 \pm 1.6 \\
P<0.01\end{array}$ & $\begin{array}{l}6.1 \pm 1.0 \\
P<0.01\end{array}$ \\
\hline$\Delta$ Plaque volume $\left(\mathrm{mm}^{3}\right)$ & $\begin{array}{c}1.8 \pm 1.5 \\
P=0.3\end{array}$ & $\begin{array}{c}-0.5 \pm 1.4 \\
P=0.8\end{array}$ & $\begin{array}{c}1.0 \pm 1.0 \\
P=0.3\end{array}$ & $\begin{array}{c}-2.2 \pm 1.5 \\
P=0.2\end{array}$ & $\begin{array}{c}-0.8 \pm 1.6 \\
P=0.6\end{array}$ & $\begin{array}{c}1.5 \pm 1.1 \\
P=0.2\end{array}$ \\
\hline$\Delta$ Plaque burden $(\%)$ & $\begin{array}{l}2.1 \pm 0.7 \\
P<0.01\end{array}$ & $\begin{array}{c}1.0 \pm 0.6 \\
P=0.1\end{array}$ & $\begin{array}{c}-0.1 \pm 0.5 \\
P=0.8\end{array}$ & $\begin{array}{c}-1.1 \pm 0.7 \\
P=0.1\end{array}$ & $\begin{array}{c}-2.2 \pm 0.8 \\
P<0.01\end{array}$ & $\begin{array}{c}-1.1 \pm 0.5 \\
P=0.03\end{array}$ \\
\hline \multicolumn{7}{|l|}{ Plaque composition } \\
\hline$\Delta$ Fibrous volume $\left(\mathrm{mm}^{3}\right)$ & $\begin{array}{l}1.6 \pm 0.9 \\
P=0.08\end{array}$ & $\begin{array}{c}0.8 \pm 0.8 \\
P=0.3\end{array}$ & $\begin{array}{l}1.2 \pm 0.5 \\
P=0.03\end{array}$ & $\begin{array}{c}-0.8 \pm 0.8 \\
P=0.3\end{array}$ & $\begin{array}{c}-0.4 \pm 0.9 \\
P=0.6\end{array}$ & $\begin{array}{c}0.4 \pm 0.6 \\
P=0.5\end{array}$ \\
\hline$\Delta$ Fibrous volume $(\%)$ & $\begin{array}{l}0.7 \pm 0.3 \\
P=0.02\end{array}$ & $\begin{array}{c}0.4 \pm 0.2 \\
P=0.1\end{array}$ & $\begin{array}{l}0.6 \pm 0.2 \\
P=0.01\end{array}$ & $\begin{array}{c}-0.3 \pm 0.2 \\
P=0.3\end{array}$ & $\begin{array}{c}-0.1 \pm 0.2 \\
P=0.7\end{array}$ & $\begin{array}{c}0.2 \pm 0.2 \\
P=0.4\end{array}$ \\
\hline$\Delta$ Fibro-lipidic volume $\left(\mathrm{mm}^{3}\right)$ & $\begin{array}{c}0.6 \pm 0.6 \\
P=0.3\end{array}$ & $\begin{array}{c}0.4 \pm 0.6 \\
P=0.5\end{array}$ & $\begin{array}{l}0.6 \pm 0 . \\
P=0.09\end{array}$ & $\begin{array}{c}-0.3 \pm 0.5 \\
P=0.6\end{array}$ & $\begin{array}{c}-0.04 \pm 0.5 \\
P=0.9\end{array}$ & $\begin{array}{c}0.2 \pm 0.4 \\
P=0.6\end{array}$ \\
\hline$\Delta$ Fibro-lipidic volume (\%) & $\begin{array}{r}0.7 \pm 0.3 \\
P=0.04\end{array}$ & $\begin{array}{r}0.9 \pm 0.3 \\
P=0.01\end{array}$ & $\begin{array}{c}0.4 \pm 0.3 \\
P=0.3\end{array}$ & $\begin{array}{c}0.1 \pm 0.3 \\
P=0.7\end{array}$ & $\begin{array}{c}-0.4 \pm 0.4 \\
P=0.3\end{array}$ & $\begin{array}{c}-0.5 \pm 0.3 \\
P=0.09\end{array}$ \\
\hline$\Delta$ Necrotic core volume $\left(\mathrm{mm}^{3}\right)$ & $\begin{array}{c}0.3 \pm 0.3 \\
P=0.3\end{array}$ & $\begin{array}{c}0.1 \pm 0.2 \\
P=0.7\end{array}$ & $\begin{array}{c}-0.1 \pm 0.1 \\
P=0.5\end{array}$ & $\begin{array}{c}-0.2 \pm 0.1 \\
P=0.2\end{array}$ & $\begin{array}{c}-0.4 \pm 0.2 \\
P=0.07\end{array}$ & $\begin{array}{c}-0.2 \pm 0.2 \\
P=0.3\end{array}$ \\
\hline$\Delta$ Necrotic core volume $(\%)$ & $\begin{array}{c}-0.6 \pm 0.2 \\
P=0.02\end{array}$ & $\begin{array}{c}-0.7 \pm 0.2 \\
P<0.01\end{array}$ & $\begin{array}{c}-0.5 \pm 0.2 \\
P<0.01\end{array}$ & $\begin{array}{c}-0.1 \pm 0.2 \\
P=0.7\end{array}$ & $\begin{array}{c}0.1 \pm 0.3 \\
P=0.7\end{array}$ & $\begin{array}{c}0.2 \pm 0.2 \\
P=0.3\end{array}$ \\
\hline$\Delta$ Calcium volume $\left(\mathrm{mm}^{3}\right)$ & $\begin{array}{c}-0.2 \pm 0.05 \\
P<0.01\end{array}$ & $\begin{array}{c}-0.2 \pm 0.05 \\
P<0.01\end{array}$ & $\begin{array}{c}-0.1 \pm 0.05 \\
P<0.01\end{array}$ & $\begin{array}{c}0.03 \pm 0.05 \\
P=0.6\end{array}$ & $\begin{array}{c}0.1 \pm 0.05 \\
P=0.07\end{array}$ & $\begin{array}{c}0.1 \pm 0.05 \\
P=0.2\end{array}$ \\
\hline$\Delta$ Calcium volume $(\%)$ & $\begin{array}{c}-0.8 \pm 0.2 \\
P<0.01\end{array}$ & $\begin{array}{c}-0.6 \pm 0.1 \\
P<0.01\end{array}$ & $\begin{array}{c}-0.5 \pm 0.1 \\
P<0.01\end{array}$ & $\begin{array}{c}0.2 \pm 0.1 \\
P=0.1\end{array}$ & $\begin{array}{l}0.4 \pm 0.2 \\
P=0.07\end{array}$ & $\begin{array}{c}0.1 \pm 0.1 \\
P=0.3\end{array}$ \\
\hline
\end{tabular}

Values are normalised to $10 \mathrm{~mm}$ length; mean \pm standard error of the mean; ${ }^{*}$ two-sided student $t$-test.

difference. Plaque burden showed no significant differences for the comparison between centre $A$ versus $C$ and $D$, respectively, and $B$ versus $\mathrm{C}$; the other comparisons between the different centres were significant $(P \leq 0.03)$, however, the (absolute) differences were small, ranging from 0.6-1.1\%. Overall intraclass correlation and range of the individual between-centre comparisons (within brackets) were for vessel, lumen, plaque volume and plaque burden 0.98 (0.97-0.99), 0.92 (0.86-0.95), 0.95 (0.94-0.98) and $0.86(0.78-0.92)$, respectively. The limits of agreement (i.e., 2 SD of mean difference) were small and similar for the different comparisons. The range of the standard deviation of the relative between centre differences for vessel, lumen, plaque volume and plaque burden were 2.5-3.0\%, 6.4$9.3 \%, 6.7-10.1 \%$ and $5.9-9.3 \%$, respectively. An example of the agreement is presented in Figure 2; the measurement reproducibility of vessel volume was particularly high. Measurement reproducibility was not influenced by the size of the measured volumes.

\section{Composition}

VH-IVUS assessments of plaque composition were highly correlated for the different comparisons. Overall intraclass correlation and range of the individual between-centre comparisons (within brackets) for (absolute) fibrous, fibro-lipidic, necrotic core and calcified volume were 0.95 (0.92-0.97) 0.93 (0.90-0.96), 0.99 (0.98-1.00), and 1.00 (1.00-1.00), respectively. There were small significant differences for fibrous and calcified volumes (Table 2). The limits of agreement (i.e., 2 SD of mean difference) for compositional data were somewhat higher, but similar for the different comparisons. The range of the standard deviation of the relative between centre differences for fibrous, fibro-lipidic, necrotic core and calcified volume were 10.6-15.9\%, 20.2-28.9\%, 8.9$13.9 \%$ and $6.4-13.9 \%$, respectively. An example of the agreement is presented in Figure 2. Necrotic core and calcified volumes showed the highest measurement reproducibility. Smaller compositional volumes showed a slightly higher between-centre variability.

\section{Discussion}

In the present multicentre study we assessed the between-centre reproducibility of measurements of vessel geometry and plaque composition in mild-to-moderately diseased atherosclerotic coronary segments. The overall intraclass correlations were high for geometric as well as compositional data (>0.86). The relative between-centre differences were low for vessel, lumen, and plaque volume $(<4 \%,<9 \%$, and $<3 \%$, respectively) as well as for fibrous, fibro-lipidic, necrotic core, and calcified plaque components $(<6 \%$, $<11 \%,<3 \%$, and $<8 \%$, respectively) demonstrating mild but 


\section{Vessel geometry}

Relative $\Delta$ vessel volume (\%)

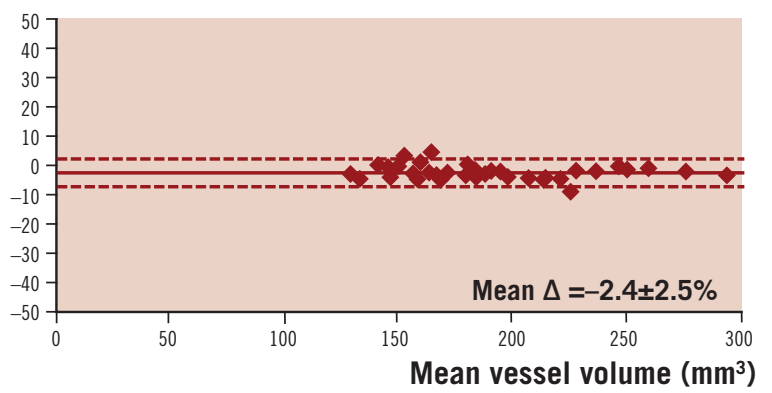

Relative $\Delta$ plaque volume (\%)

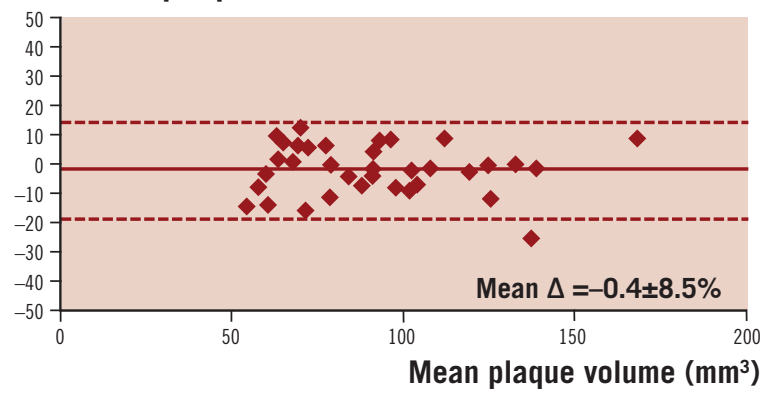

Relative $\Delta$ lumen volume (\%)

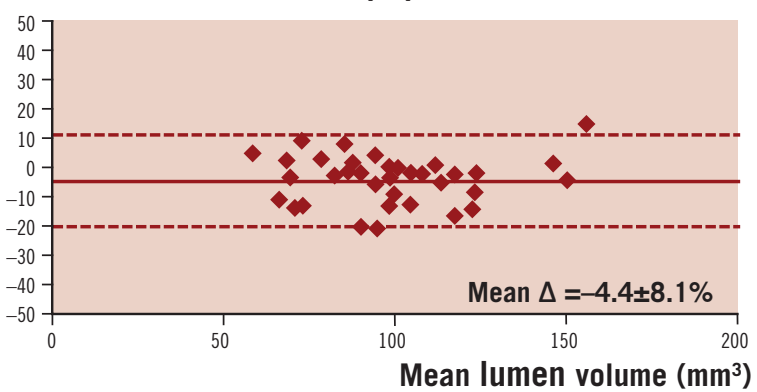

Relative $\Delta$ plaque burden (\%)

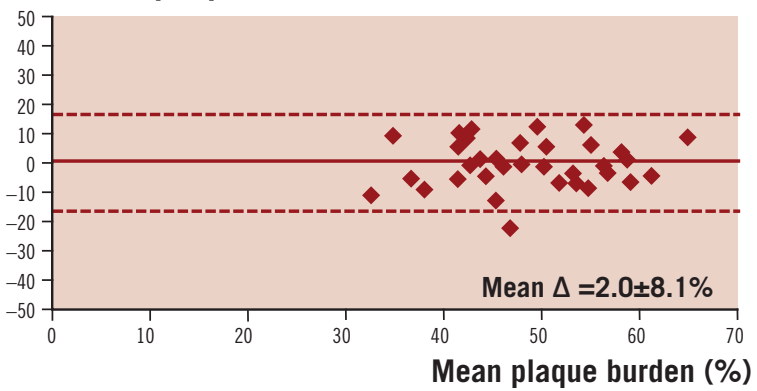

Plaque composition

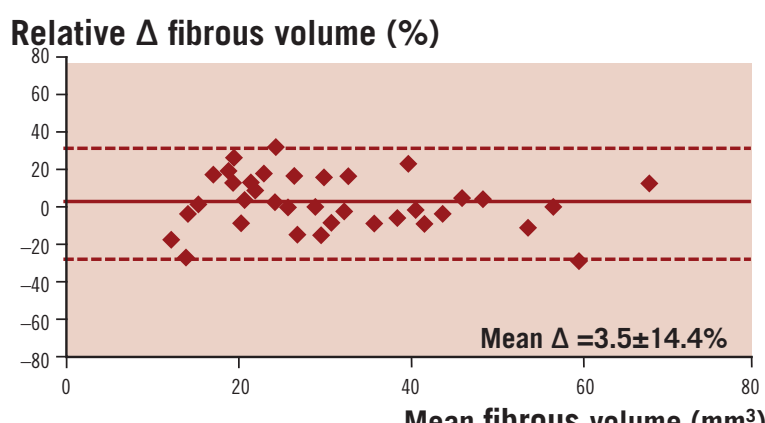

Mean fibrous volume $\left(\mathrm{mm}^{3}\right)$

Relative $\Delta$ necrotic-core volume (\%)

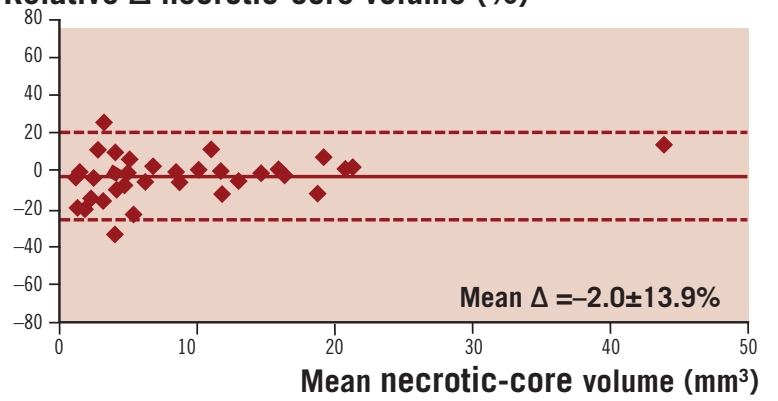

Relative $\Delta$ fibro-lipidic volume (\%)

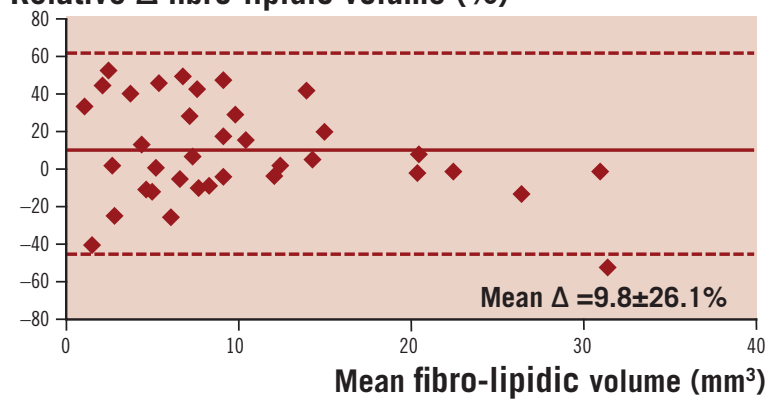

Relative $\Delta$ calcium volume (\%)

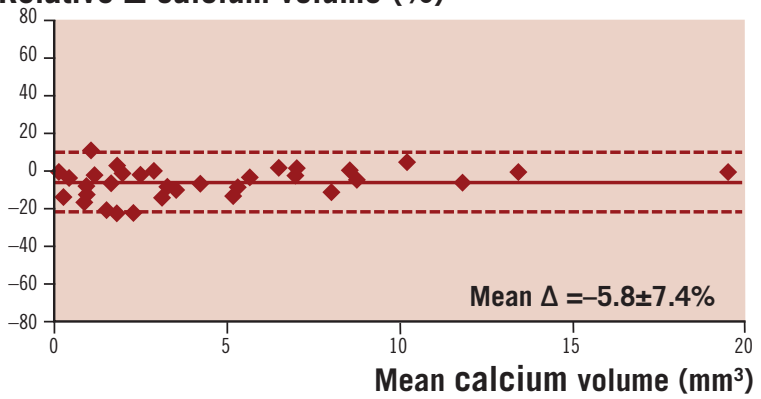

Figure 2. Example of the agreement of repeated VH-IVUS measurements of geometric and compositional volumes for two centres. Corresponding analyses were also performed for the other possible comparisons between the four centres, showing similar results (see text for further results).

systematic differences, most likely as a result of manual contour editing. Plaque burden measurements showed more differences $(<5 \%)$, resulting in a higher variability and somewhat lower, but still good, intraclass correlations. This higher variability might be explained by the addition of variabilities of the variables themselves that are required for the calculation of plaque burden.

\section{Measurement reproducibility}

Serial VH-IVUS is increasingly used for the assessment of the natural history of atherosclerosis, vascular remodelling, and pharmacological interventions. ${ }^{1,4,17-21}$ As changes in plaque size and composition are often small, ${ }^{20}$ good measurement reproducibility is important. 9,10,14,26 
Rodriguez-Granillo et al investigated the measurement variability of VH-IVUS cross-sectional data obtained from 16 non-significant coronary atherosclerotic lesions in a single-centre study; ${ }^{14}$ interobserver variability of geometric and compositional data was larger than inter-catheter variability particularly for indirect measurements such as plaque area. For geometric cross-sectional area measurements the relative intra-observer difference was $\leq 3 \%$ for lumen and vessel cross-sectional area and $<11 \%$ for plaque crosssectional area; conversely, compositional measurements showed larger measurement variability of up to $24 \% .^{14}$

Prasad et al assessed VH-IVUS measurements in significant lesions prior to and following percutaneous coronary intervention and demonstrated that volumetric VH-IVUS measurements of coronary segments had a high measurement reproducibility. ${ }^{23}$ The agreement between repeated geometric cross-sectional IVUS analyses was somewhat higher than that of cross-sectional compositional VH-IVUS analyses. ${ }^{23}$

We previously demonstrated a relatively high intra- and interobserver reproducibility of volumetric geometric and compositional VH-IVUS data in 33 mild-to-moderately diseased coronary segments. ${ }^{22}$ Nevertheless, all these previous studies investigated the measurement variability of analysts from a single centre (or core lab) who were trained in one and the same way.

As demonstrated in the present multicentre study, measurements by analysts from four different IVUS centres with different training programs showed somewhat higher measurement variability and minor (though often significant) measurement differences. Differences may have resulted from slight systematic over- or underestimation of the lumen and/or vessel borders and/or differences in the interpolation of the vessel contour at the site of side branches. Necrotic core and calcified plaque volume (often located more centrally in the plaque) showed a particularly high measurement reproducibility while fibrous and fibro-lipidic volume showed more variability. This is in agreement with previous observations suggesting that variation in tracing the lumen contour (i.e., inclusion of the lumen in plaque and media volume) may result in misinterpretation of blood inside the lumen as fibrous and fibro-lipidic tissue. This may explain why these two tissue types show the largest relative difference between two centres. The centres with small lumen volume measured the largest content of fibrous and fibro-lipidic tissue (Table 2). Misinterpretation of thrombus and soft plaque adjacent to the lumen could theoretically have introduced a large measurement variability; however, this is extremely unlikely in the examined patient population with stable angina pectoris. ${ }^{2,6,9,12,27}$

Our present data underline the necessity to analyse such data at a single site - ideally in an experienced core-lab. As an alternative, one may consider that analysts of different centres undergo an identical training to assure a very similar (or identical) way of analysis. In addition, our findings suggest that pooling VH-IVUS data from different studies that are analysed at different IVUScentres may be problematic. Awareness of the inter-observer differences may be particularly important in serial pharmacological intervention trials where small changes in plaque and/or vessel size as well as plaque composition may be expected. ${ }^{20}$

\section{Limitations}

In the present study, IVUS analyses were performed offline in coronary segments obtained from patients with stable angina pectoris; therefore our findings cannot be extrapolated to VH-IVUS reproducibility studies in an online setting or in patients with acute coronary syndromes. The coronary segments of the study population contained mild-to-moderate atherosclerotic disease. The study did not address significant coronary lesions with particularly small lumen dimensions (e.g., a lumen area $<4.0 \mathrm{~mm}^{2}$ ), in which the recognition of the lumen border may be more difficult and measurement variability may be higher.

Similar to other studies with IVUS and VH-IVUS, we excluded very tortuous and severely calcified vessels that could have led to nonuniform pullbacks and/or inability to detect the (external) vessel contour. ${ }^{14,22}$ The variability between different IVUS catheters or pullback devices, repeated pullbacks, and independent selections of the segment of interest were not addressed in the present multicentre study that focused on the assessment of measurement reproducibility in predefined segments with mild-to-moderate coronary disease.

\section{Conclusion}

These findings underline the necessity to centrally analyse IVUS data obtained in multicentre studies that address mild-tomoderately diseased coronary arteries. However, pooling VH-IVUS data from different studies analysed at different centres may be problematic.

\section{References}

1. Böse D, von Birgelen C, and Erbel R. Intravascular ultrasound for the evaluation of therapies targeting coronary atherosclerosis. J. Am. Coll. Cardiol. 2007;49:925-932.

2. Di Mario C, Gorge G, Peters R, Kearney P, Pinto F, Hausmann D, von Birgelen C, Colombo A, Mudra H, Roelandt J, and Erbel R. Clinical application and image interpretation in intracoronary ultrasound. Study Group on Intracoronary Imaging of the Working Group of Coronary Circulation and of the Subgroup on Intravascular Ultrasound of the Working Group of Echocardiography of the European Society of Cardiology. Eur. Heart J. 1998;19:207-229.

3. Mintz GS, Nissen SE, Anderson WD, Bailey SR, Erbel R, Fitzgerald PJ, Pinto FJ, Rosenfield K, Siegel RJ, Tuzcu EM, and Yock PG. American College of Cardiology Clinical Expert Consensus Document on Standards for Acquisition, Measurement and Reporting of Intravascular Ultrasound Studies (IVUS). A report of the American College of Cardiology Task Force on Clinical Expert Consensus Documents. J. Am. Coll. Cardiol. 2001;37:1478-1492.

4. Schartl M, Bocksch W, Koschyk DH, Voelker W, Karsch KR, Kreuzer J, Hausmann D, Beckmann S, and Gross M. Use of intravascular ultrasound to compare effects of different strategies of lipid-lowering therapy on plaque volume and composition in patients with coronary artery disease. Circulation 2001;104:387-392.

5. Fujii K, Carlier SG, Mintz GS, Wijns W, Colombo A, Böse D, Erbel R, de Ribamar Costa J, Jr., Kimura M, Sano K, Costa RA, Lui J, Stone GW, Moses JW, and Leon MB. Association of plaque characterization by intravascular ultrasound virtual histology and arterial remodeling. Am. J. Cardiol. 2005;96:1476-1483. 
6. Garcia-Garcia HM, Mintz GS, Lerman A, Vince DG, Margolis P, van Es GA, Morel MA, Nair A, Virmani R, Burke AP, Stone GW, and Serruys PW. Tissue characterisation using intravascular radiofrequency data analysis: recommendations for acquisition, analysis, interpretation and reporting. Eurolntervention 2009;5:177-189.

7. Garcia-Garcia HM, Gonzalo N, Regar E, and Serruys PW. Virtual histology and optical coherence tomography: from research to a broad clinical application. Heart 2009;95:1362-1374.

8. Hong MK, Mintz GS, Lee CW, Suh J, Kim JH, Park DW, Lee SW, Kim YH, Cheong SS, Kim JJ, Park SW, and Park SJ. Comparison of virtual histology to intravascular ultrasound of culprit coronary lesions in acute coronary syndrome and target coronary lesions in stable angina pectoris. Am. J. Cardiol. 2007;100:953-959.

9. König A, Klauss V. Virtual histology. Heart 2007;93:977-982.

10. Mehta SK, McCrary JR, Frutkin AD, Dolla WJ, and Marso SP. Intravascular ultrasound radiofrequency analysis of coronary atherosclerosis: an emerging technology for the assessment of vulnerable plaque. Eur. Heart J. 2007;28:1283-1288.

11. Nair A, Kuban BD, Tuzcu EM, Schoenhagen P, Nissen SE, and Vince DG. Coronary plaque classification with intravascular ultrasound radiofrequency data analysis. Circulation 2002;106:2200-2206.

12. Nasu K, Tsuchikane E, Katoh O, Vince DG, Virmani R, Surmely JF, Murata A, Takeda $\mathrm{Y}$, Ito $\mathrm{T}$, Ehara M, Matsubara T, Terashima M, and Suzuki T. Accuracy of in vivo coronary plaque morphology assessment: a validation study of in vivo virtual histology compared with in vitro histopathology. J. Am. Coll. Cardiol. 2006;47:2405-2412.

13. Okubo M, Kawasaki M, Ishihara Y, Takeyama U, Kubota T, Yamaki T, Ojio S, Nishigaki K, Takemura G, Saio M, Takami T, Minatoguchi S, and Fujiwara $\mathrm{H}$. Development of integrated backscatter intravascular ultrasound for tissue characterization of coronary plaques. Ultrasound Med. Biol. 2008;34:655-663.

14. Rodriguez-Granillo GA, Vaina S, Garcia-Garcia HM, Valgimigli M, Duckers E, van Geuns RJ, Regar E, van der Giessen WJ, Bressers M, Goedhart D, Morel MA, de Feyter PJ, and Serruys PW. Reproducibility of intravascular ultrasound radiofrequency data analysis: implications for the design of Iongitudinal studies. Int. J. Cardiovasc. Imaging 2006;22:621-631.

15. von Birgelen C, Slager CJ, Di Mario C, de Feyter PJ, and Serruys PW. Volumetric intracoronary ultrasound: a new maximum confidence approach for the quantitative assessment of progression-regression of atherosclerosis? Atherosclerosis 1995;118 Suppl:S103-S113.

16. Peters RJ, Kok WE, Rijsterborgh H, van Dijk M, Koch KT, Piek JJ, David GK, and Visser CA. Reproducibility of quantitative measurements from intracoronary ultrasound images. Beat-to-beat variability and influence of the cardiac cycle. Eur. Heart J. 1996;17:1593-1599.
17. Hong MK, Park DW, Lee CW, Lee SW, Kim YH, Kang DH, Song JK, Kim JJ, Park SW, and Park SJ. Effects of statin treatments on coronary plaques assessed by volumetric virtual histology intravascular ultrasound analysis. JACC. Cardiovasc. Interv. 2009;2:679-688.

18. Nasu K, Tsuchikane E, Katoh O, Tanaka N, Kimura M, Ehara M, Kinoshita Y, Matsubara T, Matsuo H, Asakura K, Asakura Y, Terashima M, Takayama T, Honye J, Hirayama A, Saito S, and Suzuki T. Effect of fluvastatin on progression of coronary atherosclerotic plaque evaluated by virtual histology intravascular ultrasound. JACC. Cardiovasc. Interv. 2009;2:689-696.

19. Nozue T, Yamamoto S, Tohyama S, Umezawa S, Kunishima T, Sato A, Miyake S, Takeyama Y, Morino Y, Yamauchi T, Muramatsu T, Hibi K, Sozu $\mathrm{T}$, and Michishita I. Treatment with statin on atheroma regression evaluated by intravascular ultrasound with Virtual Histology (TRUTH Study): rationale and design. Circ. J. 2009;73:352-355.

20. Serruys PW, Garcia-Garcia HM, Buszman P, Erne P, Verheye S, Aschermann M, Duckers H, Bleie O, Dudek D, Botker HE, von Birgelen C, D'Amico D, Hutchinson T, Zambanini A, Mastik F, van Es GA, van der Steen AF, Vince DG, Ganz P, Hamm CW, Wijns W, and Zalewski A. Effects of the direct lipoprotein-associated phospholipase $A(2)$ inhibitor darapladib on human coronary atherosclerotic plaque. Circulation 2008;118:1172-1182

21. Toi T, Taguchi I, Yoneda S, Kageyama M, Kikuchi A, Tokura M, Kanaya T, Abe S, Matsuda R, and Kaneko N. Early Effect of LipidLowering Therapy With Pitavastatin on Regression of Coronary Atherosclerotic Plaque. Circ. J. 2009;73:1466-72.

22. Hartmann M, Mattern ES, Huisman J, van Houwelingen GK, de Man FH, Stoel MG, Danse PW, Louwerenburg HW, and von Birgelen C. Reproducibility of volumetric intravascular ultrasound radiofrequencybased analysis of coronary plaque composition in vivo. Int. J. Cardiovasc. Imaging 2009;25:13-23.

23. Prasad A, Cipher DJ, Prasad A, Mohandas A, Roesle M, Brilakis ES, Banerjee S. Reproducibility of intravascular ultrasound virtual histology analysis. Cardiovasc. Revasc. Med. 2008;9:71-77.

24. Jensen LO and Thayssen P. Accuracy of electrocardiographicgated versus nongated volumetric intravascular ultrasound measurements of coronary arterial narrowing. Am. J. Cardiol. 2007;99:279-283.

25. Bland JM and Altman DG. Statistical methods for assessing agreement between two methods of clinical measurement. Lancet 1986;1:307-310.

26. Regar E, Werner F, Klauss V, Siebert U, Henneke KH, Rieber J, König A, Theisen $\mathrm{K}$, and Mudra H. IVUS analysis of the acute and longterm stent result using motorized pullback: intraobserver and interobserver variability. Catheter. Cardiovasc. Interv. 1999;48:245-250.

27. Frutkin AD, Mehta SK, McCrary JR, and Marso SP. Limitations to the use of virtual histology-intravascular ultrasound to detect vulnerable plaque. Eur. Heart J. 2007;28:1783-1784. 